\title{
EL IMPACTO DE LOS DERECHOS EUROPEOS (CEDH Y DERECHO DE LA UNIÓN) EN LA JUSTICIA CONSTITUCIONAL ITALIANA
}

\author{
GiUsePPE MARTINICO ${ }^{1}$
}

RESUMEN: El objetivo de este artículo es presentar las principales tendencias de la jurisprudencia del Tribunal Constitucional italiano en materia de derecho de la Unión Europea (UE) y del Convenio Europeo de Derechos Humanos (CEDH). El artículo se divide en tres partes: la primera parte ofrece una breve panorámica de las normas constitucionales principales con referencia al derecho internacional público; la segunda está dedicada a la jurisprudencia constitucional en tema de derecho de la UE, mientras que la tercera aborda la jurisprudencia relacionada con el Convenio europeo.

Palabras clave: Italia, CEDH, Derecho UE, Europa.

ABSTRACT: This article aims to present the main trends in the case law of the Italian Constitutional Court about the impact of European Union (EU) Law and the European Convention of Human Rights (ECHR) on the national legal system. The article is divided into three parts: the first part offers a brief overview of the Italian norms devoted to public international law. The second part is devoted to the constitutional case law concerning EU law while the third part is about the case law concerning the ECHR.

KEY words: Italy, ECHR, EU Law, Italian Constitutional court, Europe.

SumARIO: I. Objetivo y estructura del artículo; II. La Constitución italiana y el derecho internacional público: una panorámica de las previsiones relevantes; III. La jurisprudencia constitucional relevante en materia de derecho de la Unión: una breve panorámica; IV. El Convenio Europeo de Derechos Humanos y la jurisprudencia del Tribunal Constitucional italiano; V. Conclusiones.

1 Giuseppe Martinico es Profesor Titular (Professore Associato) de derecho público comparado en la Scuola Superiore S. Anna, Pisa, e investigador en el Centro de Estudios sobre el Federalismo de Turín. Contacto: <Giuseppe.martinico@sssup.it>. Recibido: 24 octubre 2015; aceptado: 22 noviembre 2015. 


\section{i. Objetivo y estructura del artículo}

$4 \begin{aligned} & \text { l objetivo de este artículo es presentar las principales ten- } \\ & \text { dencias de la jurisprudencia del Tribunal Constitucional } \\ & \text { italiano en materia de derecho de la Unión Europea (UE) y }\end{aligned}$ del Convenio Europeo de Derechos Humanos (CEDH). Para hacerlo no me limitaré a una mera reconstrucción cronológica, sino que trataré de destacar las líneas de referencia que caracterizan el impacto de estos dos conjuntos de normas sobre la jurisprudencia del Tribunal Constitucional.

En ese sentido, este artículo no ofrece una descripción de la jurisprudencia de los últimos años, sino que intentará definir el impacto de los derechos europeos a la luz de indicadores constantes que se encontraron en la jurisprudencia constitucional a lo largo de esos años. El artículo se divide en tres partes: la primera parte ofrece una breve panorámica de las normas constitucionales principales con referencia al derecho internacional público; la segunda está dedicada a la jurisprudencia constitucional en tema de derecho de la UE, mientras que la tercera aborda la jurisprudencia relacionada con el Convenio Europeo.

El caso italiano resulta interesante por diversas razones: la primera es la insuficiencia del parámetro formal, es decir, la imposibilidad de entender los efectos ocasionados por los derechos europeos sin ir más allá de la redacción de las normas constitucionales. La segunda es el progresivo abandono del auto-aislamiento del Tribunal Constitucional en cuestiones de derecho europeo (tanto con referencia al CEDH como al derecho de la UE). En este sentido los últimos años se han caracterizado por la aceptación, por primera vez, del mecanismo prejudicial contenido en el artículo 267 del Tratado de Funcionamiento de la Unión Europea (TFUE) por la Corte Costituzionale, a través de la declaración de inconstitucionalidad de una ley nacional en conflicto con el derecho de la UE (visto como 
norma interpuesta) ${ }^{2}$ a la luz del artículo 117 de la Constitución ${ }^{3}$ -que, como veremos, también ha reconocido a posteriori formalmente el principio de primacía del derecho de la UE- y por un progresivo enfrentamiento entre jueces comunes (es decir, ordinarios y administrativos) y el Tribunal Constitucional con referencia a la vexata questio de la inaplicación del derecho nacional a la luz del CEDH.

Como advertiremos, para solucionar el problema, el Tribunal Constitucional quiso centralizar el control de convencionalidad (contrôle de conventionnalité), incorporándolo en el área de constitucionalidad y aceptando "comprometerse" entonces en cuestiones de conflicto entre el derecho del CEDH y el derecho nacional (probablemente por la ausencia, en el caso del CEDH, de un mecanismo comparable al procedimiento prejudicial contenido en el artículo 267 del TFUE que garantiza un papel central al juez común nacional). Otro elemento característico ha sido la doctrina de los contra-límites, que sigue teniendo actualmente un sentido particular en la jurisprudencia italiana y representa el verdadero punto de distinción entre el derecho del CEDH y el derecho de la UE según la Corte Costituzionale.

2 Carlo, Lavagna, Problemi di giustizia costituzionale sotto il profilo della "manifesta infondatezza", Milano Giuffrè, 1957, 28; Massimo Siclari, Le norme interposte nel giudizio di costituzionalità, C.E.D.A.M., Padova, 1992.

Scholars have minted the wording 'interposed provision' to individualize the cases in which a constitutional standard can be invoked only indirectly in a constitutional judicial proceeding, because different primary provisions are inserted between the constitutional standard and the reported provisions (suspected of being unconstitutional).

Francesca Biondi Dal Monte y Filippo Fontanelli “The Decisions Nos. 348 and 349/2007 of the Italian Constitutional Court: The Efficacy of the European Convention in the Italian Legal System", 7 German Law fournal (2008) 891, 897.

${ }^{3}$ Cristina Napoli, "La Corte dinanzi ai 'vincoli derivanti dall'ordinamento comunitario': tra applicazione dell'art. 117, primo comma e rispetto dei poteri interpretativi della Corte di Giustizia", disponible en: <www.forumcostituzionale.it>. 
Mientras se exige que el CEDH respete toda la Constitución (no solo su núcleo esencial), al derecho de la UE se le impone el respeto de los contra-límites. Esto es consecuencia de la diferente cobertura constitucional que esos derechos reciben por la Carta fundamental italiana según el Tribunal Constitucional: al derecho de la UE se aplican un conjunto de normas (entre otras el artículo 11 concerniente a la cesión de soberanía) que sólo en parte son aplicables al GEDH.

\section{LA CONSTITUCIÓN ITALIANA Y EL DERECHO INTERNACIONAL PÚBLICO: UNA PANORÁMICA DE LAS PREVISIONES RELEVANTES}

Italia se caracteriza por una fuerte tradición dualista. Hay dos disposiciones fundamentales de la Constitución italiana relativas a la relación entre el derecho internacional y nacional: los artículos $10^{4}$ y $11 .^{5}$

Estos dos artículos constituyen la primera diferencia importante que existe en este campo en Italia, la distinción entre las normas generales del derecho internacional y los tratados internacionales.

4 Art. 10:

L'ordinamento giuridico italiano si conforma alle norme del diritto internazionale generalmente riconosciute.

La condizione giuridica dello straniero è regolata dalla legge in conformità delle norme e dei trattati internazionali.

Lo straniero, al quale sia impedito nel suo paese l'effettivo esercizio delle libertà democratiche garantite dalla Costituzione italiana, ha diritto d'asilo nel territorio della Repubblica secondo le condizioni stabilite dalla legge.

Non è ammessa l'estradizione dello straniero per reati politici.

5 "Art. 11:

L'Italia ripudia la guerra come strumento di offesa alla libertà degli altri popoli e come mezzo di risoluzione delle controversie internazionali; consente, in condizioni di parità con gli altri Stati, alle limitazioni di sovranità necessarie ad un ordinamento che assicuri la pace e la giustizia fra le Nazioni; promuove e favorisce le organizzazioni internazionali rivolte a tale scopo. 
En cuanto a las primeras, el artículo 10 establece un procedimiento automático de adopción, en el sentido de que tales normas se incorporan directamente en el sistema italiano. Según los estudiosos italianos, las normas generales del derecho internacional (que corresponderían al derecho internacional consuetudinario) pertenecen al nivel constitucional. ${ }^{6}$

De acuerdo con algunos autores, el derecho consuetudinario internacional vigente antes de la entrada en vigor de la Constitución italiana podría prevalecer sobre las disposiciones constitucionales (debido a la aplicación del criterio cronológico), pero esto no se aplica con respecto a los principios que pertenecen al núcleo intocable señalado por el artículo 139 de la Constitución a través de la ambigua fórmula de "forma republicana" (este núcleo intocable, según la sentencia n. 1146/1988, incluye también los supremos principios incluidos en la primera parte de la Constitución italiana). ${ }^{7}$

En cuanto a los tratados internacionales, en ciertos casos es necesario que exista una ley nacional que los transforme en derecho nacional; sin embargo, no se requiere la intervención del legislador nacional para todos los tratados, ya que el artículo 80 constitucional $^{8}$ establece la necesidad de una legislación que autorice la ratificación solo con referencia a algunos tratados particulares. El

6 Giuseppe de Vergottini, Diritto costituzionale, CEDAM, Padova, 2004, 32.

7 Para una panorámica sobre este debate: Antonio Cassese, "Commento art.10 della Costituzione", en Giuseppe Branca (ed.), Commentario della Costituzione, vol. Principi fondamentali. Artt.1-12, Zanichelli, Bolonia, 1975, 485, 502. Según Quadri, el procedimiento automático debería ser aplicado también a los tratados internacionales, pero ésta es una visión minoritaria. Dicha teoría se basa en el hecho que uno de los principios generales del derecho internacional es el principio pacta sunt servanda. Rolando Quadri, Diritto internazionale pubblico, Liquori, Nápoles, 1989, 64.

8 Art. 80:

Le Camere autorizzano con legge la ratifica dei trattati internazionali che sono di natura politica, o prevedono arbitrati o regolamenti giudiziari, o importano variazioni del territorio od oneri alle finanze o modificazioni di legg". 
procedimiento de ratificación se rige también por el artículo 87,9 que reconoce al Presidente de la República la competencia para ratificar los tratados internacionales. Cuando se requiere la intervención de las cámaras, el Parlamento interviene con una ley. Según la mayoría de los expertos, esto confiere una fuerza primaria en la jerarquía de la ley nacional a las normas derivadas de los tratados internacionales. A pesar de ello, la Constitución italiana reconoce una fuerza especial a las leyes relacionadas con las obligaciones internacionales. El artículo 75, párrafo 2 (dedicado al referéndum), establece que: "No se admitirá el referéndum para las leyes tributarias y presupuestarias, de amnistía y de indulto, ni de autorización para ratificar tratados internacionales".

Además de los artículos 10 y 11, otra disposición fundamental está consagrada en el artículo 117, que se discutirá más adelante. Esto explica por qué, desde el principio, tanto el CEDH como la legislación comunitaria se consideraron como fuentes primarias en el ordenamiento jurídico italiano.

Otra característica importante del ordenamiento jurídico italiano es el hecho de que, a diferencia de otros países como Portugal y España, no se otorga un valor específico a los tratados de derechos humanos. Este es otro punto importante a considerar al analizar los acontecimientos judiciales de la Corte Costituzionale en este campo.

El nuevo apartado 1 del artículo 117 de la Constitución italiana, consagra expresamente el límite que las obligaciones supranacionales representan para la legislación nacional, al establecer que: "el Poder Legislativo será ejercido por el Estado y por las Regiones dentro de los términos de la Constitución, así como de las obliga-

9 Art. 87:

Il Presidente della Repubblica è il capo dello Stato e rappresenta l'unità nazionale.

Può inviare messaggi alle Camere [...]

Accredita e riceve i rappresentanti diplomatici, ratifica i trattati internazionali, previa, quando occorra, l'autorizzazione delle Camere. 
ciones que deriven del ordenamiento comunitario y de los compromisos internacionales". En cuanto a la jurisprudencia, veremos que esta disposición provocó innovaciones interesantes en la doctrina del Tribunal Constitucional italiano. Poco después de la reforma, la interpretación de esta disposición creó una división entre los estudiosos. ${ }^{10}$ Según algunos, el artículo 117 , apartado 1, simplemente codificó la situación preexistente, como si fuera una especie de asentimiento escrito a posteriori sobre la primacía ${ }^{11}$ europea. Otra parte de la doctrina destacó la importancia de la posición constitucional dada a la primacía europea, y afirmaron que el artículo 117 allanó el camino para la aceptación de la tesis monista. ${ }^{12}$

III. LA JURISPRUDENCIA CONSTITUCIONAL RELEVANTE EN MATERIA DE DERECHO DE LA UNIÓN: UNA BREVE PANORÁMICA

El Tribunal Constitucional contempló originalmente la base para la aceptación del derecho comunitario (y de su primacía y efecto directo) en el artículo 11 de la Constitución italiana. ${ }^{13}$ Esta acepta-

10 Roberto Chieppa, "Nuove prospettive per il controllo di compatibilità comunitaria da parte della Corte costituzionale", [2007] Il Diritto dell'Unione Europea 493, 499 ff; Antonio Ruggeri, "Riforma del titolo V e giudizi di 'comunitarietà' delle leggi", 2007, disponible en:<http://www.associazionedeicostituzionalisti.it/ dottrina/ordinamentieuropei/ruggeri.html $>$.

11 Cesare Pinelli, "I limiti generali alla potestà legislativa statale e regionale e i rapporti con l'ordinamento comunitario" [2001] 5 Foro italiano 194.

12 Francesco Paterniti, "La riforma dell'art. 117, 1 co. della Costituzione e le nuove prospettive dei rapporti tra ordinamento giuridico nazionale e Unione Europea" [2004] Giur. Cost., no. 2, 2101; Alessandro Pajno, "Il rispetto dei vincoli derivanti dall'ordinamento comunitario come limite alla potestà legislativa nel nuovo Titolo V della Costituzione" [2003] Le Istituzioni del federalismo, 814.

13 Sobre la relación entre el derecho de la Unión y la Constitución italiana: Marta Cartabia, Principi inviolabili e integrazione europea, Giuffrè, Milano, 1995; Marta Cartabia y Alfonso Celotto, "La giustizia costituzionale in Italia dopo la Carta di Nizza", [2002] Giur. Cost., 4477 ss.; Marta Cartabia y Joseph H.H. Weiler, L'Italia in Europa, Il Mulino, Bologna, 2000. Filippo Donati, Diritto comunitario e 
ción, sin embargo, no se produjo inmediatamente. Por el contrario, fue el resultado de una larga serie de decisiones, provocadas principalmente por la ausencia de una cláusula europea explícita.

De hecho, el artículo 11 fue concebido originalmente para hacer frente a la pertenencia de Italia a las organizaciones internacionales como las Naciones Unidas, y no para justificar el derecho supranacional (un fenómeno que no se conocía cuando la Constitución italiana entró en vigor). En este sentido, un cambio muy importante fue la reforma constitucional, en el año 2001, del Título V de la segunda parte de la carta fundamental italiana a través de la cual se modificaron los contenidos del artículo 117.

sindacato di costituzionalità, Giuffrè, Milano, 1995; Antonio La Pergola, "Il giudice costituzionale italiano di fronte al primato e all'effetto diretto del diritto comunitario: note su un incontro di studio", [2003] Giur. cost., 2419 ss.; Antonio Tizzano, "Die Italienische Corte Costituzionale und der Gerichtshof der Europäischen Union", [2010] Europäische Grundrechte Zeitung, 1 ss; Antonio Tizzano, "La Corte di giustizia delle Comunità europee e i diritti nazionali", [2005] Il Diritto dell'Unione Europea, 839-852; Antonio Tizzano, "Ancora sui rapporti tra Corti europee: principi comunitari e c.d. controlimiti costituzionali", [2007] Il Diritto dell'Unione Europea, , 734-744; Giuseppe Morbidelli, "La tutela dei diritti tra la Corte del Lussemburgo e Corte Costituzionale", in Giuseppe Morbidelli y Francesco Donati (a cura di), Una costituzione per l'Unione europea, Giappichelli, Torino, 9-61. Alessandro Pace, "La sentenza Granital, ventitré anni dopo", disponible en: <www.associazionedeicostituzionalisti.it/dottrina/ordinamentieuropei/La $\% 20$ sentenza $\% 20$ Granital,\%2023\%20anni\%20dopoII.pdf>. Publicada también en [2007] Studi sull'integrazione europea, 451-467); Federico Sorrentino, "La Costituzione italiana di fronte al processo di integrazione europea", [1993] Quaderni costituzionali, 81 ss.; Federico Sorrentino, "Nuovi profili costituzionali dei rapporti tra diritto interno e diritto internazionale e comunitario", [2002] Diritto pubblico comparato ed europeo, 1355-1361; Federico Sorrentino, "Ai limiti dell'integrazione europea: primato delle fonti o delle istituzioni?", [1994] Politica del diritto, 189-201; Giuseppe Sperduti, "Un chiarimento in diritto comunitario e diritto interno", [1979] Rivista diritto internazionale, 72-75; Giuseppe Sperduti, "Diritto comunitario e diritto interno nella giurisprudenza della Corte Costituzionale italiana e della Corte di giustizia delle Comunità europee: un dissidio da sanare", [1978] Giur. Cost., 791-819; Roberto Bin, "Gli effetti del diritto dell'Unione nell'ordinamento italiano e il principio di entropia", in AA.VV., Scritti in onore di Franco Modugno, I, Jovene, Napoli, 2011, 363-383. 
Para describir sintéticamente la jurisprudencia constitucional italiana en este ámbito voy a centrarme en tres elementos: la doctrina de la impermeabilidad, ${ }^{14}$ la doctrina de los contra-límites y el progresivo abandono del auto-aislamiento del Tribunal Constitucional italiano.

Si echamos un vistazo a la historia de la jurisprudencia de la Corte Costituzionale en relación con el derecho de la UE, es posible notar una salida progresiva de la visión dualista pura que la Corte había adoptado al principio. A lo largo de los años esta pureza se superó y el Tribunal Constitucional - refiriéndose a la relación entre ordenamiento interno y supranacional - en un segundo momento comenzó a hablar de dos "sistemas jurídicos coordinados, pero autónomos e independientes". ${ }^{15}$ En este sentido, se puede hablar de una (limitada) flexibilización del concepto de soberanía, ${ }^{16}$ con referencia a esta progresiva evolución de la jurisprudencia italiana.

A pesar de este acercamiento, la ampliación de competencias de la Unión (y antes de las Comunidades) a menudo ha dado lugar a un cierto grado de tensión entre el poder del Tribunal italiano y el Tribunal de Justicia de la Unión Europea (TJUE), cada vez que entra en juego el reparto de competencias.

En primer lugar, el Tribunal de Justicia ha obtenido progresivamente la confianza de los jueces ordinarios nacionales, que desempeñan un papel fundamental también en el proceso de control de

14 Filippo Fontanelli y Giuseppe Martinico, "Between procedural impermeability and constitutional openness: the 102 and decision of the Italian Constitutional Court", [2010] European Law Fournal, 345-364.

15 Corte Costituzionale, decisiones n. 183/73 y n. 170/84, disponible en: $<w w w$. cortecostituzionale.it>.

16 En cierto sentido parecido a lo señalado por Victor Ferreres Comella, "La Constitución española ante la clausola de primacía del Derecho de la Unión europea. Un comentario a la Declaración 1/2004 del Tribunal Constitucional 1/2004", en Antonio López Castillo, Alejandro Saiz Arnaiz y Victor Ferreres Comella (eds), Constitución española y constitución europea Centro de Estudios Políticos y Constitucionales, Madrid, 2005, 77, 80-89. 
constitucionalidad en el ámbito nacional. Tal influencia se tradujo en ciertos casos en el deterioro de la relación entre los jueces ordinarios y el Tribunal constitucional: cada vez que los jueces ordinarios quieren obtener una explicación acerca de la relación entre el derecho de la Unión y derecho nacional (incluso a nivel constitucional a veces), no se refieren a la Corte Costituzionale, sino al TJUE.

Esto es una consecuencia de la situación de auto-aislamiento del Tribunal constitucional italiano, que normalmente prefiere no abordar cuestiones relativas a la relación entre ordenamientos jurídicos. Basta recordar aquí que, en 2002, el Tribunal Constitucional resolvió solamente diez casos (de 500 en total) ${ }^{17}$ relacionados con el ordenamiento jurídico comunitario.

Con referencia a la jurisprudencia constitucional sobre la posición del derecho comunitario en el ordenamiento interno, originalmente, en la sentencia 14/1964, ${ }^{18}$ la Corte italiana interpretó la relación entre derecho interno y derecho comunitario a la luz del criterio cronológico, lex posterior derogat priori (ya que el acto nacional que cubre formalmente los efectos del derecho comunitario es una ley).

Más tarde, en la sentencia 183/1973 ${ }^{19}$ la Corte cambió su posición y afirmó que la base constitucional de la primacía de la legislación comunitaria se encontraba en el artículo 11 de la Constitución italiana.

Como se ha dicho ya, esta disposición fue concebida originalmente para justificar la pertenencia de Italia a las Naciones Unidas. La adhesión a la UE, de hecho, impone limitaciones a la soberanía de los objetivos que van claramente más allá de la paz y la justicia entre las naciones, por lo tanto el Tribunal Constitucional se vio

17 Marta Cartabia y Alfonso Celotto, "La giustizia costituzionale in Italia dopo la Carta di Nizza", [2002] Giurisprudenza Costituzionale, 4477.

18 Corte Costituzionale, sentencia n. 14/1964, disponible en: <www. cortecostituzionale.it>.

19 Corte Costituzionale, sentencia n. 183/1973, disponible en: <www. cortecostituzionale.it>. 
obligado a "manipular" el significado original del artículo 11, con el fin de adaptarse a estas limitaciones. La consecuencia de esto fue la centralización del control sobre los conflictos entre derecho comunitario y derecho nacional.

En el 1984, ${ }^{20}$ el Tribunal Constitucional italiano empezó a aceptar que el juez ordinario ejerciera el control del respeto de la primacía comunitarias a la luz de la doctrina Simmenthal, ${ }^{21}$ intentando conciliar esta apertura con su monopolio en el control de constitucionalidad. Técnicamente, según el Tribunal Constitucional italiano, el juez nacional no puede anular las normas nacionales en conflicto con el derecho supranacional (ya que el juez nacional común no realiza un control de validez, cosa que implicaría la pertenencia de ambas normas al mismo sistema normativo); solamente puede dejar de aplicar la norma nacional incompatible con el derecho comunitario provisto de efecto directo (tratándose de reglamentos, pero lo mismo es aplicable también para ciertos tipos de directivas - como sucedió en el auto 64/1990- y para las sentencias interpretativas que doten de significado a normas de derecho de la Unión Europea (UE) provistas de efectos directos (véanse las sentencias $113 / 1985^{22}$ y $\left.389 / 1989^{23}\right)$. En este sentido, la inaplicación implica una suspensión de eficacia y el juez nacional actúa con un control que insiste en la eficacia y no en la validez del derecho nacional.

Por otro lado, el Tribunal Constitucional trató de mantener papel propio sin excepciones. De hecho, casi todos los tribunales constitucionales europeos, en principio, se negaron a aceptar las

20 Corte Costituzionale, sentencia n. 170/1984, disponible en: <www. cortecostituzionale.it>.

21 Amministrazione delle Finanze dello Stato v Simmenthal SpA., Case 106/77, ECR 1978, p. 629.

22 Corte Costituzionale, sentencia n. 113/1985, disponible en: <www. cortecostituzionale.it>.

${ }^{23}$ Corte Costituzionale, sentencia n. 389/1989, disponible en: <www. cortecostituzionale.it>. 
visiones monistas peligrosas, con el fin de preservar la identidad constitucional de sus ordenamientos jurídicos ${ }^{24}$

Además, el Tribunal Constitucional italiano también ha levantado algunas barreras (los "controlimiti") ${ }^{25}$ contra la penetración de la legislación comunitaria, en caso de una potencial violación de los principios fundamentales que la Corte Costituzionale está obligada a proteger. Así, otra característica del enfoque del Tribunal Constitucional italiano frente al derecho de la UE es sin duda la doctrina de los contra-límites, elaborada por el Tribunal Constitucional en el 1973, ${ }^{26}$ poco después de la famosa decisión Internationale Handesgeselschaft ${ }^{27}$ del Tribunal de Justicia de la UE.

En Internationale Handesgeselschaft, el TJUE afirmó la primacía del derecho comunitario sobre el derecho nacional, incluidos los principios constitucionales nacionales. ${ }^{28}$

Al respecto, la posición italiana -junto con la alemana- es relevante para una comprensión completa de las razones de la "resistencia" de los tribunales constitucionales frente a la doctrina del TJUE. Los tribunales constitucionales han pretendido mantener su propio papel (el de guardianes de la identidad constitucional nacional), sin excepciones. Para hacerlo se han levantado algunas barreras defini-

24 Sobre este punto, véase Marta Cartabia, Principi inviolabili e integrazione europea, más recientemente, sobre el 4.2 TUE, Elke Cloots, National Identity en EU Law, Oxford University Press, Oxford, 2015; F. Millet, L'Union européenne et l'identité constitutionnelle des États membres, L.G.D.J, Paris, 2013.

25 Paolo Barile, "Ancora su diritto comunitario e diritto interno", en Studi per il XX anniversario dell'Assemblea costituente, VI, Firenze, 1969, 49.

26 Corte Costituzionale, sentencia n. 183/1973, disponible en: <www. cortecostituzionale.it>.

27 TJUE 11/70 Internationale Handesgesellschaft [1970] ECR 1125.

28 "La alegación de violaciones de los derechos fundamentales, tal como están formulados por la Constitución de un Estado miembro, o de los principios de una estructura constitucional nacional no puede afectar a la validez de un acto de la Comunidad o a su efecto en el territorio de dicho Estado". 
tivas contra la penetración del derecho de la UE con el fin de definir los principios fundamentales de los ordenamientos jurídicos.

Hipotéticamente, si una disposición de la UE entrase en conflicto con los principios fundamentales del ordenamiento jurídico nacional, el Tribunal Constitucional podría declarar la inconstitucionalidad de la ley nacional de ejecución de los Tratados europeos, provocando una "ruptura" entre los ordenamientos jurídicos nacionales y el derecho supranacional. Los Tribunales Constitucionales de hecho normalmente tienen jurisdicción sobre la legislación nacional (incluyendo las leyes nacionales y la ejecución de los tratados), pero no sobre las previsiones comunitarias. Estas últimas están más allá de su jurisdicción, ya que, de acuerdo con su argumentación, pertenecen a otro orden legal.

A partir de este enfoque, se puede entender por qué el Tribunal Constitucional ha negado la posibilidad de evaluar la validez de las disposiciones del derecho de la UE, ya que la aceptación de esta opción implicaría la adhesión a la teoría monista. A través de una ficción legal (en la cual el Tribunal asume el control de la validez de la ley de ejecución porque pertenece al ordenamiento), el Tribunal Constitucional trata de defender el núcleo duro del ordenamiento jurídico mediante la preservación de la autonomía formal.

La identificación de estas barreras a la integración europea representa la esencia de la doctrina de los contra-límites (dottrina dei controlimiti), elaborada por el Tribunal Constitucional italiano en la sentencia Frontini ${ }^{29}$ (pero véase también el asunto 170/84, la sentencia Granital). ${ }^{30}$ La consecuencia de una posible declaración de inconstitucionalidad de la ley de ejecución de los tratados europeos

29 Corte Costituzionale, sentencia n.183/1973, Frontini: [1974] 2 GMLR 372.

30 Corte Costituzionale, sentencia n.170/1984, Granital: [1984] CMLR 756: "nella sent. n. 183 del 27 dicembre 1973, già avvertito come la legge di esecuzione del Trattato possa andar soggetta al suo sindacato, in riferimento ai principi fondamentali del nostro ordinamento costituzionale e ai diritti inalienabili della persona umana”. Sobre este punto, véase M. Cartabia, Principi inviolabili. 
podría significar la retirada de Italia de la UE. De acuerdo con Cartabia, ${ }^{31}$ en estos dos casos el control sobre los contra-límites se concibe como una forma de llevar a cabo un control excepcional sobre el respeto de las condiciones de constitucionalidad de la adhesión de Italia a la UE.

A la luz de esta reconstrucción, los contra-límites funcionan como condiciones para evaluar la legitimidad de las limitaciones de la soberanía aceptadas a la luz de la adhesión de Italia a las Comunidades (o a la Unión). Más adelante (con la decisión núm. 232/1989, la sentencia Fragd), ${ }^{32}$ la naturaleza de la doctrina de los contra-límites cambió, transformándose de un control excepcional en un control "ordinario" de la compatibilidad del derecho UE con los principios fundamentales de la Constitución. En este sentido, como ha escrito Cartabia, " $i$ 'controlimiti' concepiti all'origine come condizioni di limitazioni di sovranità divengono una limitazione al primato del diritto comunitario". ${ }^{33}$ De hecho, en la sentencia Fragd, el Tribunal Constitucional italiano admitió implícitamente que el posible conflicto con la Constitución no sería motivo de nulidad de la ley de ejecución del Tratado CE, sino solo la no aplicabilidad de la norma de la UE. ${ }^{34}$

Otro elemento de desacuerdo entre el Tribunal Constitucional italiano y el TJUE ha sido, por muchos años, la reticencia del primero a concebirse como juez a la luz del artículo 267 del TFUE (el antiguo artículo 234 del Tratado de la Comunidad Europea). Al mismo tiempo, el Tribunal Constitucional italiano, tratando de combinar los fundamentos de la supremacía constitucional y de la primacía del derecho comunitario (utilizando la terminología del Tribunal

31 Marta Cartabia, Principi inviolabili, 110.

32 Corte Costituzionale, sentencia n. 232/1989, disponible en: <www. cortecostituzionale.it>. In English: Fragd (1990) 27 CML Rev 93.

33 Marta Cartabia y Joseph Weiler, H.H, L'Italia in Europa, 172.

34 Ibidem. 
Constitucional español ${ }^{35}$ ), ha evitado tradicionalmente utilizar el derecho comunitario como parámetro de constitucionalidad.

Después de la aceptación de la doctrina Simmenthal, que convierte al juez común en el verdadero defensor del derecho de la UE, el Tribunal Constitucional italiano ha intentado aislarse de todo lo concerniente a los conflictos entre derecho nacional y derecho de la Unión, concibiéndolos como conflictos de legalidad y no de constitucionalidad. ${ }^{36}$

A lo largo de los años esto ha producido una impermeabilidad de la jurisprudencia constitucional al derecho de la UE que se combinaba con la reticencia de plantearle cuestiones prejudiciales al TJUE.

Sin embargo, el Tribunal Constitucional italiano ha admitido progresivamente algunas excepciones a esta impermeabilidad, es decir, algunas situaciones en las que esta doctrina podía ser mitigada. Estas excepciones pueden ser esquemáticamente las siguientes:

1. Los procedimientos por vía principal (o directos); ${ }^{37}$

35 Tribunal Constitucional de España, declaración n. 1/2004, disponible en: $<$ www.tribunalconstitucional.es>.

36 Corte Costituzionale, sentencias n. 384/1994 y n. 94/1995, disponible en: $<w w w . c o r t e c o s t i t u z i o n a l e . i t>$ Sobre el funcionamiento del control de constitucionalidad en Italia véase: Roberto Romboli, "El control de constitucionalidad de las leyes en Italia", [1999] Teoría y realidad constitucional, 179-205. En Italia el control de constitucionalidad puede articularse por dos vías: por vía principal o directa (es decir, un procedimiento donde el Estado o las Regiones pueden impugnar una ley regional o estatal) y otro por vía incidental o indirecta (es decir, un procedimiento originado por una cuestión de constitucionalidad planteada por un juez común en el curso de un juicio).

37 Art. 127 de la Constitución italiana:

Cuando el Gobierno estime que una ley regional excede de la competencia de la Región, podrá plantear la cuestión de constitucionalidad ante el Tribunal Constitucional dentro de los sesenta días siguientes a su publicación.

Cuando una Región estime que una ley o un acto con fuerza de ley del Estado o de otra región lesiona su ámbito de competencia, podrá entablar una cuestión de constitucionalidad ante el Tribunal Constitucional dentro de los sesenta días siguientes a la publicación de la ley o del acto con fuerza de ley. 
2. Los casos de conflicto entre las normas nacionales y las normas del derecho de la Unión que carezcan de efecto directo (en este caso no es utilizable el instrumento de la inaplicación) $;^{38}$

3. Casos de violación de los contra-límites nacionales; ${ }^{39}$

4. En el caso del control sobre la admisibilidad del referéndum abrogativo: en las sentencias $64 / 1990^{40}$ y $41 / 2000,{ }^{41}$ por ejemplo, unas directivas comunitarias se consideraron relevantes para el control de admisibilidad, ya que su contenido condujo al rechazo de las propuestas de referéndum que tenían como intención abrogar normas nacionales adoptadas para cumplir con las obligaciones europeas (véase también la sentencia n. 45/2000) ${ }^{42}$. De esta manera, la Corte amplió el límite establecido en el art. 75 de la Constitución italiana, según la cual "no se admitirá el referéndum para las leyes tributarias y presupuestarias, de amnistía y de indulto, ni de autorización para ratificar tratados internacionales"; y

5. En caso de choque permanente entre las normas internas y los principios fundamentales de la Unión. ${ }^{43}$

38 Como se ha dicho tambien en Granital (Corte Costituzionale, n. 170/84 cit.), véase Pasquale Costanzo, Luca Mezzetti y Antonio Ruggeri, Lineamenti di diritto costituzionale dell'Unione europea, Giappichelli, Torino, 2006, 284.

39 Corte Costituzionale, sentencias n. 183/73 y 170/84 cit.

40 Corte Costituzionale, sentencia n. 64/1990, disponible en: <www. cortecostituzionale.it>.

41 Corte Costituzionale, sentencia n. 41/2000, disponible en: <www. cortecostituzionale.it>.

42 Corte Costituzionale, sentencia n. 45/2000, disponible en: <www. cortecostituzionale.it>. Véase, Marta Cartabia y Joseph H. H. Weiler, L'Italia in Europa, 188.

43 Corte Costituzionale, sentencia n.286/1986, disponible en: <www. cortecostituzionale.it>. 
La distinción entre los procedimientos directos e indirectos (es decir, principal e incidental) es crucial para entender las recientes evoluciones de la jurisprudencia del Tribunal Constitucional en materia de derecho de la UE.

Al faltar en los procedimientos por vía principal, el rol del juez común (que, como hemos visto, es el defensor principal de la primacía del derecho UE a la luz de la doctrina Simmental), el Tribunal Constitucional tuvo que aceptar su -involucramiento- participación en los casos de conflicto con el derecho de la UE en las sentencias 384/1994 y 94/1995.

En particular, en la sentencia n. 384/1994 el Tribunal Constitucional reconoce que, debido a la dinámica particular de los procedimientos directos, su negativa a considerar las cuestiones de conflicto con el derecho UE implicaría una peligrosa brecha en la protección de los derechos y una violación del principio de seguridad jurídica.

Por lo tanto, se puede decir que, debido a las características únicas de los procedimientos por vía principal, la posibilidad de involucrar a la Corte Constitucional se justifica sólo por la ausencia del juez ordinario. A la luz de esta distinción, en la sentencia 129/2006, la Corte Costituzionale declaró que -como ya había tenido la oportunidad de aclarar (véase las sentencias n. 406/2005 y 166/2004)- las directivas de la Unión pueden funcionar como normas interpuestas ("norme interposte"), integrando el contenido del art. 117, apartado 1, de la Constitución que, como hemos visto, reconoce en las obligaciones supranacionales un límite a la potestad legislativa.

No extraña entonces, que en el procedimiento por vía principal el Tribunal Constitucional haya aceptado plantear, a partir del 2008, la cuestión prejudicial al TJUE. En efecto, el 15 de abril de $2008,{ }^{44}$ por primera vez en su historia, la Corte Costituzionale italiana acordó remitir una cuestión prejudicial al Tribunal de Justicia.

44 Corte Costituzionale, auto n. 103/2008, disponible en: <www. cortecostituzionale.it>. Véase también la sentencia 102/2008, disponible en: $<w w w . c o r t e c o s t i t u z i o n a l e . i t>$. 
Sin embargo, el Tribunal Constitucional italiano limitó su decisión de remisión a los procedimientos directos, enfatizando la estructura diferente que caracteriza al proceso indirecto del control de constitucionalidad.

Coherentemente con su jurisprudencia anterior, el auto del Tribunal Constitucional se basa mucho en la distinción entre el procedimiento directo (donde el Tribunal Constitucional actúa como verdadero juez, que decide sobre un litigio entre dos partes, Estado y Regiones) e indirecto (que es un procedimiento "sin partes"45 y donde el verdadero juzgador de la cuestión es el juez remitente).

Sin embargo, recientemente, el Tribunal constitucional italiano cambió otra vez su jurisprudencia y planteó una cuestión prejudicial incluso dentro de un procedimiento incidental. ${ }^{46}$ Esa decisión fue vista como un punto de inflexión, ya que el Tribunal constitucional así pasó de una forma de diálogo que había sido visto como "parcial" a un "diálogo pleno". ${ }^{47}$

Sin embargo, cuando el Tribunal constitucional no aceptaba el mecanismo del artículo 267 del TFUE, esta estrategia tampoco conducía directamente a la denegación automática de cualquier forma de diálogo con el TJUE. Por el contrario, en aquellos años, el Tribunal italiano había ideado algunas formas alternativas de diálogo (lo que en otros escritos llamé "hidden dialogue”, o diálogo

45 Véase el libro de Roberto Romboli, Il giudizio costituzionale incidentale come processo senza parti, Giuffrè, Milano, 1985.

46 Corte Costituzionale, auto n. 207/2013, disponible en: <www.cortecostituzionale.it>. Véase, Barbara Guastaferro, "La Corte costituzionale ed il primo rinvio pregiudiziale in un giudizio di legittimità costituzionale in via incidentale: riflessioni sull'ordinanza n. 207 del 2013", disponible en: <http://www.forumcostituzionale.it/wordpress/images/stories/pdf/documenti_forum/giurisprudenza/2013/0028_nota_207_2013_guastaferro.pdf>.

47 Oreste Pollicino, "From partial to full dialogue with Luxembourg: The last cooperative step of the Italian Constitutional Court", [2014] European Constitutional Law Review, 1, 143. 
escondido $)^{48}$ con el Tribunal de Luxemburgo con el fin de llegar a un compromiso necesario entre el respeto a las obligaciones de la UE y la preservación del núcleo constitucional.

Por diálogo escondido quiero decir todo un conjunto de técnicas jurisprudenciales plasmadas por los Tribunales Constitucionales que les han permitido dialogar con el TJUE, independientemente de la aceptación del procedimiento prejudicial (que representa la vía oficial y formal de diálogo). ${ }^{49}$

48 Véase Giuseppe Martinico, "Judging in the Multilevel Legal Order: Exploring The Techniques Of 'Hidden Dialogue'”, [2010] King's Law fournal, 257-281:

From the domestic courts' perspective, there are two ways of interacting with the EGJ. One is the 'official' route provided by article 267 TFEU (although this is entirely governed by the interpretative rival, the EGJ). The other is the parallel and informal route whose dynamics are mostly discretionary, where both the procedures and the outcome of such interaction can be negotiated. Constitutional courts have historically preferred the latter method, and one can easily understand why, if we evoke, once again, the idea of interpretive competition. Given the fact that the game within the ambit of the preliminary ruling is governed by the European treaties, which represent the fundamental charters of the competitor (the EGJ), national courts should experience a loss of interpretative sovereignty

Giuseppe Martinico, "Multiple loyalties and dual preliminarity: The pains of being a judge in a multilevel legal order", [2012] International fournal of Constitutional Law, 871-896, 887.

49 Giuseppe Martinico, "Multiple loyalties and dual preliminarity", 889:

Basically, the term "hidden" refers to the origin of such a dialogue: this dialogue is hidden because it is not formalized according to the wording of the European Treaties (it is non-codified). It is hidden because it is "unexplored" by the literature (which has paid attention to the preliminary ruling mechanism). Finally, it is hidden because it represents an alternative channel of dialogue if compared with the "official" route represented by the machinery set up by article 267 TFEU. Hidden dialogue demonstrates how even actions and behaviors conceived with competitive spirit can have a systemic impact, resulting in a contribution to the modification of some of the fundamental principles of the system (here understood as the multilevel legal order).

Identifiqué las siguientes técnicas de diálogo escondido: 
En mi opinión, estas técnicas de diálogo escondido no se perderán. En cambio, mi impresión es que en un futuro próximo el Tribunal Constitucional italiano se basará en este tipo de modo alternativo de diálogo en el ámbito del procedimiento indirecto, sobre todo en el mecanismo de la doble prejudicialidad (doppia pregiudizialità). ${ }^{50}$

De acuerdo con la técnica de la doble prejudicialidad, el Tribunal Constitucional puede ser llamado a resolver una cuestión de inconstitucionalidad en relación con una norma italiana en casos donde esta cuestión prejudicial está fuertemente vinculada a otra cuestión prejudicial planteada de forma contemporánea al TJUE (ya sea por el mismo o por otro juez remitente) sobre el significado o la validez de un acto de la UE.

En este escenario, tenemos dos procedimientos prejudiciales: uno concerniente a la constitucionalidad de una ley nacional (ante el Tribunal Constitucional italiano) y otro pendiente ante el TJUE (sobre la validez o interpretación de una norma de la UE).
a) Introducción de un nuevo escalón en la jerarquía de las fuentes jurídicas (Tribunal Constitucional de España, sentencia n. 28/1991);
b) Distinción entre "primacía" y "supremacía" (Tribunal Constitucional de España, declaración No. 1/2004);
c) Admisibilidad del "recurso de amparo" contra la negativa de los jueces nacionales a plantear la cuestión prejudicial ante el TJUE (Tribunal Constitucional de España, sentencia n. 58/2004);
d) Reconocimiento del efecto erga omnes para las sentencias interpretativas del TEJ (Corte Costituzionale italiana, sentencias n.. 113/1985 y 389/1989);
e) La doble prejudicialidad: (doppia pregiudizialità) (Corte Costituzionale italiana, auto n. 165/2004 y 536/1995);
f) Distinción entre "desaplicación" y "no-aplicación" (Corte Costituzionale, sentencia n. 168/91).
50 Sobre la doble prejudicialidad, véase: Marta Cartabia, "Il processo costituzionale: l'iniziativa. Considerazioni sulla posizione del giudice comune di fronte a casi di 'doppia pregiudizialità', comunitaria e costituzionale", [1997] 5 Il Foro italiano 222. Marta Cartabia, "'Taking Dialogue Seriously'. The Renewed Need for a Judicial Dialogue at the Time of Constitutional Activism in the European Union", Jean Monnet Working paper, 12/07, 2007, disponible en: <http://www.jeanmonnetprogram.org/papers/07/071201.html>. 
Si estos dos procedimientos están muy relacionados, el Tribunal Constitucional italiano puede decidir ya sea devolver la cuestión (declarándola "inadmisible") al juez común (como en la auto n. 536/1995) o bien "esperar" que el Tribunal de Justicia se pronuncie antes de decidir su cuestión de constitucionalidad (auto n. 165/2004). De esta manera, el Tribunal Constitucional le reconoce una prioridad interpretativa a las cuestiones pendientes ante el Tribunal de Justicia y de facto suspende su propio juicio, posponiendo la decisión.

Podemos notar un efecto parecido a lo requerido por el artículo 267 del TFUE (es decir, la suspensión del juicio) sin necesidad de utilizar formalmente la cuestión prejudicial ante el Tribunal Constitucional. Como podemos ver, la doble prejudicialidad es una técnica mediante la cual el Tribunal Constitucional italiano reconoce "prioridad" a las cuestiones prejudiciales ante el Tribunal de Justicia y al artículo 267 del TFUE y, al mismo tiempo, es una técnica que puede funcionar para evitar un conflicto con el Tribunal de Justicia en relación con la posible violación de los contra-límites.

En el asunto Berlusconi (auto n.165/2004), por ejemplo, el Tribunal Constitucional italiano esperó la respuesta del TJUE, preparándose para una decisión que podía ser incompatible con sus principios fundamentales (en aquel caso, el principio del favor rei).

El caso versaba sobre la interpretación de algunas directivas sobre empresas. El TJUE aborda tres cuestiones relativas al alcance de la protección de la Directiva 68/151, la interpretación del requisito de eficacia y proporcionalidad de la pena y sobre la compatibilidad de la nueva disciplina italiana introducida en el Código Civil (artículos 2621 y 2622) con el derecho de la UE. ${ }^{51} \mathrm{Al}$ mismo

51 "The Italian Courts introduced three main questions. Since the First Council Directive 68/151/EEG did not deal explicitly with publication of false accounting but rather with the mere disclosure of accounting, the Italian Courts asked whether the offence of publicizing false accounting was covered by the First Companies Directive. Secondly, the Courts asked whether the new Italian provi- 
tiempo, algunas cuestiones de constitucionalidad en relación con la disciplina italiana se plantearon ante el Tribunal Constitucional italiano. Dado que muchos de ellos estuvieron fuertemente conectados con la decisión del TJUE, la Corte Costituzionale italiana decidió esperar a que se emitiera este pronunciamiento antes de juzgar sobre la constitucionalidad del artículo 2621 y 2622 del Código Civil italiano, temiéndose una decisión de dudosa compatibilidad con su jurisprudencia sobre el favor rei. Al haberlo hecho así, se ejerció mucha presión sobre el TJUE, que al final entregó una decisión basada en una concepción muy garantista de favor rei.

Dado que el TJUE en ese caso particular dijo que "el principio de aplicación retroactiva de la pena más leve forma parte de las tradiciones constitucionales comunes a los Estados miembros, por lo que debe considerarse un principio general del Derecho comunitario cuyo respeto garantiza el Tribunal de Justicia y que el juez nacional debe respetar", el Tribunal Constitucional italiano, a la luz de esta decisión, decidió devolver su propia pregunta de constitucionalidad al juez remitente. ${ }^{52}$

sions were compatible with Article 6 of the Fourth Companies Directive 78/660/ EEC. Finally, the Italian Courts asked whether the sanctions introduced by the new legislation could be considered as effective, proportionate and dissuasive sanctions for the breaching of EC law", Flaminia Tacconi, "Casenote-Berlusconi at the European Court of Justice - C-387/02", [2006] German Law fournal, 313-322, 314.

52 Comparable, pero diferente, me parece el caso del control de convencionalidad en el sistema de la Convención americana sobre derechos humanos, que ha sido, en un cierto sentido, introducido por la misma Corte interamericana en los asuntos- entre otros- Almonacid Arellano (Corte IDH. Caso Almonacid Arellano y otros vs. Chile. Excepciones Preliminares, Fondo, Reparaciones y Costaws. Sentencia de 26 de septiembre de 2006. Serie C No. 154) y Radilla Pacheco (Corte IDH. Caso Rosendo Radilla Pacheco vs. Estados Unidos Mexicanos. Excepciones Preliminares, Fondo, Reparaciones y Costas. Sentencia de 23 de noviembre de 2009. Serie C No. 209). Diferente es la posición del Tribunal europeo de derechos humanos y esto explica también la diferente posición asumida por los Tribunales Constitutionales hacia la posibilidad de inaplicar una norma de derecho nacional en conflicto con una de la CEDH. Sobre esto véase: Giuseppe Martin- 
Gracias a la doble prejudicialidad, el Tribunal Constitucional italiano se reservó la última palabra sobre un posible conflicto, utilizando esta técnica como una pistola sobre la mesa con el fin de ejercer presión sobre el TJUE, en los casos de posible violación de contra-límites. El uso de la doble prejudicialidad por el Tribunal italiano, permite al TJUE decidir si tomar el riesgo de un "choque" jurisdiccional o no con la Corte Costituzionale.

Esta técnica se basa en un triángulo judicial y, obviamente, esto sólo puede ocurrir en el marco de un procedimiento incidental. Gracias a la doble prejudicialidad, el Tribunal Constitucional italiano puede mantener el control sobre los jueces comunes nacionales y, al mismo tiempo, ha creado un foro alternativo de diálogo simétrico con el TJUE.

iv. El Convenio Europeo de Derechos humanos y la jurisprudencia del Tribunal Constitucional italiano

Para apreciar la evolución de la jurisprudencia de la Corte Costituzionale italiana, se debe empezar por el tema de la posición original de la Consulta, la cual refleja la ya mencionada concepción dualista de la relación entre el CEDH y el derecho nacional.

Como la entrada del CEDH en el ordenamiento jurídico italiano ocurrió a través de una ley ordinaria (Ley 848/1955), el Tribunal Constitucional italiano ha considerado, por mucho tiempo y con ciertas excepciones, el CEDH como fuente siempre de nivel primario, con la consiguiente aplicación del criterio lex posterior derogat priori en el caso de conflicto entre la ley que cubre el CEDH y otra norma italiana. Este fue el caso hasta la década de 1990, cuando

ico, "A Comparative-Constitutional Overview Of ECHR And EU Law Before National Courts", [2012] European Fournal of International Law, 401-424.

Sobre el caso mexicano véase: Guillermo Enrique Estrada Adán, "Una visión del control de Convencionalidad desde el Derecho Internacional”, en Homenaje al Maestro Edmundo Elias Musi, Porrúa, México, 2013, 233- 252. 
la Corte Costituzionale cambió su enfoque y comenzó a hacer una distinción entre el contenido y la forma de las leyes que dan efecto a los tratados internacionales. ${ }^{53}$

En otras palabras, ya que desde un punto de vista material, el contenido del CEDH tiene por objeto proteger los derechos codificados en la Constitución italiana, la consecuencia era el necesario reajuste de la jurisprudencia anterior.

Otro elemento importante ha sido la reforma constitucional de 2001, con la adopción de una nueva versión del artículo 117, ya mencionado. Después de la modificación de este precepto, los jueces italianos comunes (comuni) comenzaron a inaplicar las normas nacionales en conflicto con el CEDH, aplicando la doctrina Simmenthal y el instrumento de la inaplicación al derecho del CEDH. ${ }^{54}$

En el año 2007, con las decisiones 348 y 349/2007, ${ }^{55}$ el Tribunal Constitucional italiano decidió reaccionar frente a un fenómeno que representa una excepción al régimen de control concentrado de control de constitucionalidad, centralizando a su vez el control de convencionalidad.

53 Corte Costituzionale, sentencia n. 388/1999, disponible en: <www. cortecostituzionale.it>.

54 Tribunale di Pistoria, 23 marzo 2007; Tribunale di Genova, decisión de 23 de noviembre de 2000; Corte d'Appello di Firenze, decision n.. 570/2005 y 1403/ 2006, Consiglio di Stato, decisión n. 1926/ 2002: "Some judges had already started applying this method, which comes from the judicial practice of disapplying the internal statutory norm conflicting with Community law. In some recent occasions, even the Supreme Court of Cassation (Corte di Cassazione) and the Supreme Administrative Court (Consiglio di Stato) had endorsed the use of disapplication in cases of conflict with EGvHR law, Francesca Biondi Dal Monte y Filippo Fontanelli, "The Decisions Nos. 348”, 891.

55 Corte Costituzionales, sentencias n. 348 y 349/2007, disponible en: <www. cortecostituzionale.it>. Véanse: Francesca Biondi Dal Monte y Filippo Fontanelli, "The Decisions Nos. 348 and 349/2007"; Oreste Pollicino, "The Italian Constitutional Court at the Crossroads between Constitutional Parochialism and Co-operative Constitutionalism. Judgments Nos. 348 and 349 of 22 and 24 October 2007", 4 [2008] European Constitutional Law Review 363. 
El Tribunal Constitucional, en este sentido, lanzó un mensaje muy claro al juez común, para que evitase resolver el choque entre derecho nacional y Convenio a través de la inaplicación. La solución dada por el Tribunal Constitucional, en cambio, prevé la centralización del control de convencionalidad al ser absorbido por el control de constitucionalidad.

En este sentido, como el Tribunal Constitucional ha dicho en el 2007, el CEDH puede ocasionalmente actuar como una norma interpuesta, integrando el parámetro constitucional del artículo 117 y utilizarla así para evaluar la validez de la legislación nacional.

De esta manera, el CEDH ahora tiene en Italia un rango súper-primario. Al mismo tiempo, el Tribunal Constitucional ha aclarado que el CEDH no puede ser equiparado totalmente al derecho de la UE y, por eso, debe respetar todo el conjunto de normas constitucionales y no solo su núcleo esencial (sobre este punto, como había dicho ya al principio de este artículo, la doctrina de los contra-límites contribuye a definir el diferente estatus gozado por los derechos europeos en la jurisprudencia de la Corte Costituzionale italiana).

Sin entrar en detalles, los principales contenidos de estas dos decisiones del 2007 se pueden resumir de la siguiente manera:

1. El CEDH reviste un valor súper-primario (es decir, su clasificación normativa está a medio camino entre las leyes y las normas constitucionales);

2. En algunos casos, el TEDH puede presentarse como "parámetro interpuesto" para el control de la constitucionalidad de las leyes primarias, ya que el conflicto entre ellos y el CEDH puede dar lugar a una violación indirecta de la Constitución (artículo 117);

3. Esto $\left(\mathbf{N}^{\circ} 2\right)$ no implica que el CEDH tiene un valor constitucional, dado que el $\mathrm{CEDH}$ ha de respetar toda la Constitución; 
4. No se puede extender el instrumento de la inaplicación a los conflictos entre el derecho interno y el derecho del CEDH;

5. Sin embargo, la Constitución reconoce un favor constitucional particular al Convenio y esto implica la necesidad de interpretar la legislación nacional a la luz de las disposiciones del CEDH (según la doctrina de la interpretación conforme).

Recientemente, el Tribunal Constitucional confirmó este favor interpretativo y la importancia de la jurisprudencia del Tribunal Europeo de Derechos Humanos (TEDH), considerado como un intérprete particular que, a través de su misión, convierte al GEDH en algo más que simple derecho internacional público.

Sin embargo, según el Tribunal Constitucional aún existe una gran distinción entre el derecho de la UE y el CEDH, y es esta diferencia la que representa la base de su razonamiento:

This is because, according to the constitutional judges, the ECHR legal system has distinct structural and functional legal features as compared to the European legal order. According to the Italian Constitutional Court, the EHCR is a multilateral international public law Treaty which does not entail and cannot entail any limitation on sovereignty in the terms provided by Article 11 of the Constitution. ${ }^{56}$

Otro síntoma de la importancia de la jurisprudencia del TEDH en el marco jurídico nacional, es la sentencia n. 113/201157 de la Corte Constitucional. En este asunto, la Consulta declaró que el

56 Oreste Pollicino, "The Italian Constitutional Court at the Crossroads between Constitutional Parochialism and Co-operative Constitutionalism. Judgments Nos. 348 and 349 of 22 and 24 October 2007"; Diletta Tega, I diritti in crisi, Giuffrè, Milano, 2012, 51 ss.

57 Corte costituzionale, sentencia n. 113/2011, disponible en: <www. cortecostituzionale.it>. 
artículo 630 c. 1 Let. (a) del Código procesal penal era inconstitucional, en la parte en la que no permite la reapertura o revisión en el caso de la decisión pasada de un juzgado, lo cual se consideró una violación del derecho de la Convención. Al mismo tiempo, aún hoy algunos jueces nacionales continúan inaplicando las leyes nacionales en conflicto con el CEDH. ${ }^{58}$

Se pueden identificar diferentes razones para ello:

1. A veces los jueces no han entendido la posición del Tribunal Constitucional o no conocen la diferencia entre el CEDH y el derecho de la UE; 59

2. En otros casos, los jueces demuestran conocer la jurisprudencia de la Corte Costituzionale, pero han malentendido el sentido del nuevo artículo 6 del Tratado UE (TUE), que, después de la entrada en vigor del Tratado de Lisboa, prevé la futura adhesión de la UE al Convenio. En otras palabras, estos jueces piensan que después de la entrada en vigor del artículo 6 del TUE e independientemente de la conclusión del acuerdo de adhesión a la UE el CEDH es ya parte integrante del derecho de la $\mathrm{UE} ;{ }^{60}$

3. Finalmente, hay casos de evidente desobediencia civil donde los jueces comunes afirman conocer la posición del

58 Ilaria Carlotto, "I giudici comuni e gli obblighi internazionali dopo le sentenze n. 348 e n. 349 del 2007 della Corte costituzionale: un'analisi sul seguito giurisprudenziale", disponible en: <www.associazionedeicostituzionalisti. it>; Elisabetta Lamarque, "Il vincolo alle leggi statali e regionali derivante dagli obblighi internazionali nella giurisprudenza comune", 2010, disponible en: <www. associazionedeicostituzionalisti.it>.

59 Tribunale di Livorno, Sez. Lav., ordinanza del 28 ottobre 2008 en español. Véase Ilaria Carlotto, "I giudici comuni".

60 Consiglio di Stato, sentenza 2 marzo 2010, n. 1220. Sobre esta decisión, véase: Colavitti, Giuseppe y Cesare Pagotto, "Il Consiglio di Stato applica direttamente le norme CEDU grazie al Trattato di Lisbona: l'inizio di un nuovo percorso?", 2010, disponible en: <http://www.associazionedeicostituzionalisti.it/ rivista/2010/00/Colavitti-Pagotto01.pdf>. 
Tribunal italiano, pero la cuestionan al querer inaplicar el derecho nacional. ${ }^{61}$

4. El caso italiano es un óptimo ejemplo de cómo en un contexto multinivel la aplicación de una norma formalmente externa puede resultar en una guerra interna entre jueces nacionales. Es por eso que, más recientemente, el Tribunal Constitucional italiano tuvo que repetir su mensaje a los jueces comunes en el $2011 .{ }^{62}$

En este contexto se puede entender la ratio de la cuestión preliminar planteada en Kamberaj. ${ }^{63}$ Este caso se refería a la interpretación de la Directiva 2003/109 relativa al estatuto de los nacionales de terceros países residentes de larga duración y se originó a partir de una cuestión prejudicial planteada por un juez italiano, el Tribunale di Bolzano/Bozen, que había invocado el artículo 6 del TUE para poder inaplicar previsiones nacionales incompatibles con el CEDH, aplicando al Convenio la doctrina Simmenthal.

En Kamberaj, el juez remitente, entre otras cosas, preguntó:

si, en caso de conflicto entre una norma de derecho nacional y el CEDH, la referencia a éste que hace el artículo 6 del TUE obliga al juez nacional a aplicar directamente las previsiones del Convenio, en el caso de autos el artículo 14 del mismo así como el artículo 1 del Protocolo $\mathrm{n}^{\mathrm{o}}$ 12, y a no aplicar la norma de Derecho nacional

61 Tribunale di Ravenna, 16 enero 2008. Carlotto, "I giudici comuni".

62 Corte Costituzionale, decisión 80/2011, disponible en: <www. cortecostituzionale.it>. Antonio Ruggeri, "La Corte fa il punto sul rilievo interno della CEDU e della Carta di Nizza-Strasburgo (a prima lettura di Corte cost. n. 80 del 2011 )", disponible en: <http://www.forumcostituzionale.it/site/images/stories/ pdf/documenti_forum/giurisprudenza/2011/0002_nota_80_2011_ruggeri.pdf>.

63 C-571/10, Kamberaj, todavía no publicada; <http://curia.europa.eu/juris/ document $/$ document.jsf ?docid $=121961 \&$ mode $=$ req\&pageIndex $=1 \& \operatorname{dir}=\&$ occ $=$ first \&part $=1 \&$ text $=\&$ doclang $=\mathrm{EN} \& \mathrm{cid}=1534635>$. Véase: Giuseppe Bianco y Giuseppe Martinico, "Dialogue or Disobedience? On the domestic effects of the ECHR in light of the Kamberaj decision", [2014] European Public Law, 435-450. 
incompatible, sin tener la obligación de plantear previamente una cuestión de constitucionalidad ante la Corte costituzionale ${ }^{64}$

Como se puede observar de la redacción de la cuestión prejudicial, el juez remitente intentó utilizar el procedimiento prejudicial de una manera estratégica, pues quiso obtener nuevos argumentos desde el TJUE para superar la jurisprudencia del Tribunal Constitucional y poner fin al control centralizado de convencionalidad del Tribunal constitucional.

Esta cuestión prejudicial planteada por el Tribunale di Bolzano tiene sentido si es contextualizada en el escenario italiano, donde la posibilidad de extender la doctrina Simmenthal al CEDH ha sido concebida como una oportunidad para dar nuevos poderes a los jueces nacionales.

En Kamberaj, sabiamente desde mi punto de vista, el TJUE evitó el riesgo de verse involucrado en una guerra judicial interna, afirmando que el artículo 6 del Tratado UE no regula los efectos del CEDH en los ordenamientos jurídicos nacionales.

Por tanto, procede responder a la segunda cuestión que la referencia que hace el artículo 6 TUE, apartado 3, al CEDH no obliga al juez nacional, en caso de conflicto entre una norma de Derecho nacional y el CEDH, a aplicar directamente las previsiones de dicho Convenio y a no aplicar la norma de Derecho nacional incompatible con el mismo. ${ }^{65}$

El TJUE confirmó esta visión en Akerberg Fransson. ${ }^{66}$ Sin entrar en el detalle del análisis de estas dos decisiones, quiero limitarme a

64 C-571/10, Kamberaj, párr. 59.

65 C-571/10, Kamberaj, párr. 63.

66 G-617/10, Åkerberg Fransson, , todavía no publicada: < http://eur-lex.europa. eu/LexUriServ/LexUriServ.do?uri=CELEX:62010GJ0617:EN:HTML>.

Por lo que se refiere, en primer lugar, a las consecuencias que debe deducir un juez nacional en caso de conflicto entre el Derecho nacional y el CEDH, debe recordarse que, si bien los derechos fundamentales reconocidos por el CEDH forman parte del Derecho de la Unión como principios generales - como confirma 
tres puntos sobre Kamberaj y su impacto en la jurisprudencia del Tribunal Constitucional nacional.

En Kamberaj el TJUE parece descartar la teoría de comunitarización (por lo menos la automática) del $\mathrm{CEDH}$ por medio del artículo 6 (3) del TUE.

Al haberlo hecho así, ha transferido el tema de la relación entre el CEDH y el ordenamiento jurídico italiano al Tribunal Constitucional. El Tribunal de Luxemburgo en este sentido hizo self restraint y no cuestionó la opinión del Tribunal Constitucional italiano sobre este asunto.

Por otro lado, el TJUE afirmó que el art. 6 (3) "no obliga al juez nacional, en caso de conflicto entre una norma de Derecho nacional y el CEDH, a aplicar directamente las previsiones de dicho Convenio y a no aplicar la norma de Derecho nacional incompatible con el mismo". ${ }^{67}$

En mi opinión, este término "no obliga" puede también entenderse como "no prohíbe" en el sentido de que, si la Corte Costituzionale tuviera que modificar su punto de vista en el futuro permitiendo la inaplicación por los jueces comunes, el derecho de la UE no prohibiría este revirement.

Finalmente, el TJUE no dejó pasar la oportunidad de destacar su papel como el árbitro último del efecto directo potencial que debe darse al CEDH a la luz del derecho de la UE. El TJUE recordó, en efecto, que el artículo 6 (3) del TUE reproduce una jurisprudencia

el artículo 6 TUE, apartado 3-, y el artículo 52, apartado 3, de la Carta exige dar a los derechos contenidos en ella que correspondan a derechos garantizados por el CEDH el mismo sentido y alcance que les confiere dicho Convenio, éste no constituye, dado que la Unión no se ha adherido a él, un instrumento jurídico integrado formalmente en el ordenamiento jurídico de la Unión. En consecuencia, el Derecho de la Unión no regula la relación entre el CEDH y los ordenamientos jurídicos de los Estados miembros y no establece tampoco las consecuencias que debe deducir un juez nacional en caso de conflicto entre los derechos que garantiza dicho Convenio y una norma de Derecho nacional. (párr. 44)

67 C-571/10, Kamberaj, párr. 63. Énfasis añadido. 
consolidada, que considera la protección de los derechos fundamentales como parte de los principios generales del derecho de la UE, cuyo respeto está garantizado por el TJUE. ${ }^{68}$

De esta manera, el TJUE se ha reservado la última palabra sobre el tema del efecto directo del CEDH, actuando, como siempre, como portero - utilizando la expresión de Snyder-69 de los efectos directos en el derecho de la UE. El favor constitucional atribuido al CEDH no excluye a priori casos de conflictos o divergencias interpretativas.

En la sentencia n. 230/2012, ${ }^{70}$ el Tribunal Constitucional italiano ha enfatizado la especificidad del contexto italiano y ha demostrado que puede disentir de la interpretación dada por el Tribunal Europeo de Derechos Humanos o, mejor aun, ha establecido el deber de tomar en cuenta las particularidades de su ordenamiento y que a veces no puede automáticamente seguir la jurisprudencia relevante del Tribunal de Estrasburgo. ${ }^{71}$

68 C-571/10, Kamberaj, párr. 61.

69 Francis Snyder, "The gatekeepers: the European courts and WTO law", [2003] Common market law review, 313-367.

70 Corte Costituzionale, sentencia n. 230/2012, disponible en: <www.cortecostituzionale.it>. Antonio Ruggeri, "Ancora a margine di Corte cost. n. 230 del 2012, post scriptum", disponible en: <http://www.diritticomparati.it/2012/10/ ancora-a-margine-di-corte-cost-n-230-del-2012-post-scriptum.html> .

71 "La prima e fondamentale censura svolta dal rimettente -quella di violazione dell'art. 117, primo comma, Cost., per contrasto con l'art. 7 della CEDU, così come interpretato dalla Corte di Strasburgo- trova il suo presupposto nell'orientamento di questa Corte, costante a partire dalle sentenze n. 348 e n. 349 del 2007, in forza del quale le norme della CEDU, nel significato loro attribuito dalla Corte europea dei diritti dell'uomo, specificamente istituita per dare ad esse interpretazione e applicazione, integrano, quali «norme interposte», il parametro costituzionale evocato, nella parte in cui impone la conformazione della legislazione interna ai vincoli derivanti dagli obblighi internazionali (ex plurimis, tra le ultime, sentenze n. 78 del 2012, n. 303, n. 236 e n. 113 del 2011): ciò, peraltro, nei limiti in cui la norma convenzionale, come interpretata dalla Corte europea - la quale si pone pur sempre a livello sub-costituzionale - non venga a trovarsi in conflitto con altre conferenti previsioni della Costituzione 
Se trata da una decisión que se contextualiza en el marco de un enfrentamiento más amplio que ha llevado a decisiones como Maggio ${ }^{72}$ o Agrati $^{73}$-en materia de leyes de interpretación auténti$\mathrm{ca}^{-}$, donde el TEHD ha condenado al Estado italiano por violación del artículo 6 del Convenio.

Conviene resaltar un punto importante de la decisión. No se trata de un fenómeno aislado, pues a pesar de que le hayan reconocido una gran autoridad a la jurisprudencia del TEDH, otros tribunales constitucionales ${ }^{74}$ también han tratado a veces de distinguir su jurisprudencia de la del Tribunal Europeo.

italiana (sentenze n. 303, n. 236 e n. 113 del 2011, n. 93 del 2010, n. 317 e n. 311 del 2009), e ferma restando, altresì, la spettanza a questa Corte di un 'margine di apprezzamento e di adeguamento', che - nel rispetto della 'sostanza' della giurisprudenza di Strasburgo - le consenta comunque di tenere conto delle peculiarità dell'ordinamento in cui l'interpretazione della Corte europea è destinata ad inserirsi (sentenze n. 303 e n. 236 del 2011, n. 311 del 2009)", Corte Costituzionale, sentencia n. 230/2012, <www.cortecostituzionale.it>.

72 TEDH, Maggio e altri c. Italia, nn. 46286/09, 52851/08, 53727/08, 54486/08 e 56001/08.

73 TEDH, Agrati e altri c. Italia (n. 43549/08, 6107/09 e 5087/09. Véase también Corte Costituizionale, decision 311/2009, disponible en: <www. cortecostituzionale.it>. Sobre este enfrentamiento véase también M. Massa, "Agrati: Corte europea vs. Corte costituzionale sui limiti alla retroattività", 2011, disponible en: <http://www.forumcostituzionale.it/site/images/stories/pdf/ documenti_forum/giurisprudenza/corte_europea_diritti_uomo/0017_massa.pdf > .

74 Tribunal Constitucional de Alemania, 2 BvR 1481/04 Tribunal Constitucional de Austria, Miltner, VfSlg 11500/1987, disponible en: <http:// www.ris.bka.gvat/vfgh/>; Tribunal Supremo del Reino Unido, $R$ v. Horncastle and Others [2009] UKSG 14, para. 11 y Manchester City Council v. Pinnock [2010] UKSG 45, para. 48, donde el Tribunal Supremo dijo que:

This Court is not bound to follow every decision of the [ECtHR]. Not only would it be impractical to do so: it would sometimes be inappropriate, as it would destroy the ability of the Court to engage in the constructive dialogue ... which is of value to the development of Convention law. Of course, we should usually follow a clear and constant line of decisions ... But we are not actually bound to do so or (in theory, at least) to follow a decision of the Grand Chamber[...] Where, however, there is a clear and constant line of 
Episodios de divergencia se materializaron en otros casos, donde la Corte Costituzionale tuvo que distinguir su papel, frente al Tribunal de Estrasburgo, de una manera clara:

La norma GEDU, nel momento in cui va ad integrare il primo comma dell'art. 117 Cost., come norma interposta, diviene oggetto di bilanciamento, secondo le ordinarie operazioni cui questa Corte è chiamata in tutti i giudizi di sua competenza (sent. n. 317 del 2009). Operazioni volte non già all'affermazione della primazia dell'ordinamento nazionale, ma alla integrazione delle tutele....A differenza della Corte EDU, questa Corte, come dianzi precisato, opera una valutazione sistemica, e non isolata, dei valori coinvolti dalla norma di volta in volta scrutinata, ed è, quindi, tenuta a quel bilanciamento, solo ad essa spettante, che, nella specie, dà appunto luogo alla soluzione indicata. ${ }^{75}$

Como el antiguo Presidente del Tribunal Constitucional, Gallo, escribió en un texto preparado para una reunión celebrada en Bruselas el 24 de mayo de 2012, ${ }^{76}$ recientemente el intercambio de puntos de vista entre el Tribunal constitucional y el Tribunal de Estrasburgo se ha vuelto más y más frecuente. En principio esto le da un valor añadido a la protección de los derechos fundamentales en

decisions whose effect is not inconsistent with some fundamental substantive or procedural aspect of our law, and whose reasoning does not appear to overlook or misunderstand some argument or point of principle, we consider that it would be wrong for this Court not to follow that line.

Sobre este asunto véase: Cian Murphy, "Human Rights Law and the Challenges of Explicit Judicial Dialogue", Jean Monnet Working Paper, 10/12, disponible en: <http://centers.law.nyu.edu/jeanmonnet/papers/12/1210.html>. Sobre este fenómeno véase: Giuseppe Martinico, "A Comparative-Constitutional Overview Of ECHR And EU Law Before National Courts", [2012] European Fournal of International Law, 401-424.

75 Corte Costituzionale, sentencia n. 264/2012, disponible en: <www. cortecostituzionale.it>.

76 Franco Gallo, "Rapporti fra Corte costituzionale e Corte EDU”, Bruselas, 24 mayo 2012, disponible en: <http://www.cortecostituzionale.it/documenti/ relazioni_internazionali/RI_BRUXELLES_2012_GALLO.pdf>. 
Europa, sin embargo, como el magistrado Gallo señaló: “el trabajo de transposición de la jurisprudencia del TEDH en el ordenamiento jurídico nacional no ha sido fácil". ${ }^{77}$

Estas palabras son emblemáticos de una cierta tensión que ha surgido en los últimos años: la apertura mostrada hacia el CEDH y la jurisprudencia del TEDH por el Tribunal Constitucional en 2007 ha sido una especie de boomerang, ya que la Corte Costituzionale ha tenido desde entonces que justificar de manera expresa casi cualquier forma de desacuerdo con la interpretación del Tribunal de Estrasburgo. ${ }^{78}$ En otros casos decidió declarar la norma nacional inconstitucional sin utilizar el CEDH. ${ }^{79}$

En la sentencia n. 49/2015,80 el Tribunal constitucional italiano recordó la función preeminente realizada por el Tribunal de Estrasburgo en la interpretación del CEDH y el deber de interpretar el derecho interno de una manera conforme con éste. Por otro lado, la Corte costituzionale declaró también que los jueces nacionales no son "passivi ricettori di un comando esegetico impartito altrove nelle forme della pronuncia giurisdizionale, quali che siano le condizioni che lo hanno determinato". ${ }^{81}$ Para aclarar este punto, el Tribunal constitucional italiano hizo una distinción entre los casos en que el juez nacional tiene que hacer frente a una jurisprudencia consolidada del Tribunal de Estrasburgo y los casos en que no hay jurisprudencia consolidada.

Ciò non vuol dire, però, che questi ultimi possano ignorare l'interpretazione della Corte EDU, una volta che essa si sia consolidata in una certa direzione. Corrisponde infatti a una primaria esigenza di

77 Ibidem, p. 15.

78 Por ejemplo: Corte Costituzionale, decisión 264/2012, disponible en: $<$ www.cortecostituzionale.it>.

79 Corte Costituzionale, decisión 278/2013 y decisión n. 162/2014, disponible en: <www.cortecostituzionale.it>.

80 Corte Costituzionale, decisión 49/2015, disponible en: <www. cortecostituzionale.it>.

81 Ibidem, p. 14. 
diritto costituzionale che sia raggiunto uno stabile assetto interpretativo sui diritti fondamentali, cui è funzionale, quanto alla CEDU, il ruolo di ultima istanza riconosciuto alla Corte di Strasburgo. ${ }^{82}$

Algunos estudiosos han criticado la sentencia n. 49/2015, ya que pediría

too much of the ordinary courts, as not all courts have a deep insight into ECtHR case law nor knowledge of its official languages, and it might push the [Constitutional Court] away from fundamental rights issues, leaving these to ordinary and international courts whose main task is not to guarantee the correct interpretation and application of the Constitution. ${ }^{83}$

\section{v. Conclusiones}

En este artículo se ha tratado de ofrecer una breve panorámica de la evolución de la jurisprudencia constitucional que resulta relevante para el tema del impacto de los derechos europeos, es decir el derecho de la Unión y el CEDH.

Como hemos visto, en los dos casos el Tribunal Constitucional tuvo que alejarse progresivamente de sus posiciones iniciales, a veces enfrentándose directamente con los intérpretes de estos derechos (como en el caso del TJUE en los años setenta).

Actualmente, todavía no se puede hablar de una convergencia absoluta entre las visiones de estos tribunales; sin embargo, el Tribunal Constitucional ha aceptado los principios estructurales del derecho de la UE sin renunciar a su mandato de defensor de la Constitución.

82 Ibidem, p. 35.

83 Diletta Tega, "A National Narrative: The Constitution's Axiological Prevalence on the ECHR-A Comment on the Italian Constitutional Court Judgment No. 49/2015", [2015] Int'l f. Const. L. Blog, disponible en: < http://www.iconnectblog.com/2015/04/mini-symposium-on-cc-judgment-49-2015/>. 
Para muchas cosas, el Tribunal Constitucional italiano ha tenido una posición similar para ambos derechos europeos: ha reconocido el deber de interpretación conforme, por ejemplo y la fuerza súper-legislativa de estas normas. Al mismo tiempo, ha mostrado particular atención y respeto hacia los tribunales europeos y todo esto ocasiona que estos derechos sean peculiares si se les compara con el resto del derecho público internacional. ${ }^{84}$

Sin embargo, en muchas otras cuestiones, el Tribunal Constitucional demuestra creer todavía en la especialidad de la Unión y de concebir su derecho como sui generis, también si es comparado con el del CEDH.

Mientras muchos tribunales constitucionales o supremos han utilizado de hecho sus propias versiones de la doctrina de los contra-límites para salvaguardar el núcleo del ordenamiento constitucional (en el caso alemán, por ejemplo, el Tribunal constitucional ha utilizado la misma técnica selectiva de los contra-límites contra el Convenio), el Tribunal italiano parece pedirle al CEDH un esfuerzo todavía mayor y un límite más grande en comparación con lo requerido para el derecho de la UE, es decir, la compatibilidad con toda la Constitución.

El caso italiano demuestra también la insuficiencia de un enfoque puramente formalista para este tipo de temas. En los años ochenta, Neville Brown y McBride escribieron que la atribución del efecto directo de las previsiones del CEDH es una cuestión que depende totalmente de las constituciones nacionales. ${ }^{85}$

84 Giuseppe Martinico, "A Comparative-Constitutional Overview Of ECHR". Véase también: Helen Keller, y Alec Stone Sweet, "Assessing the Impact of the ECHR on National Legal System", en Helen Keller y Alec Stone Sweet (eds.), A Europe of Rights. The Impact of the ECHR on National Legal Systems, Oxford University Press, Oxford, 2008, 681.

85 "An individual could not however rely upon any provisions of the ECHR in a national court unless it was "capable of conferring rights on citizens of the Community which they can invoke before the courts". This requirement raises the question whether the ECHR's provisions are of direct effect. The only guide to 
Creo que algo ha cambiado, dado que hoy no se pueden entender las conclusiones del libro de Keller-Stone Sweet sobre el valor súper-primario generalmente reconocido al $\mathrm{CEDH},{ }^{86}$ sin ir más allá de la redacción de las previsiones constitucionales y esto explica por qué decidí centrarme en la jurisprudencia de los tribunales nacionales.

En cuanto a las previsiones constitucionales, se pueden observar las diferentes maneras de explicar y justificar la autoridad nacional del CEDH pero a pesar de estas diferencias, se ha apreciado que los ordenamientos europeos se están acercando progresivamente entre sí con referencia a la "posición” reconocida al CEDH en los sistemas nacionales.

Esta conclusión es independiente de la posición oficial que figura en la Constitución, o del enfoque monista o dualista de cada ordenamiento. Hoy, la cuestión del efecto directo del CEDH no depende sólo de lo que está escrito en las constituciones, sino que es algo

this is to be found in the decisions of the courts of countries whose constitutions accord the ECHR legal effect". L. Neville Brown y Jeremy McBride, "Observations on the Proposed Accession by the European Community to the European Convention on Human Rights", American Fournal of Comparative Law, (1981) 691, 695, Andrew Drzemczewski, "The Domestic Status of the European Convention on Human Rights: New Dimensions", 1 [1977] Legal Issues of European Integration, 1.

${ }^{86}$ Helen Keller y Alec Stone Sweet, "Assessing the Impact" cit, 681:

European integration -the evolution of the EU's legal system, in particular-has shaped reception in a number of crucial ways. First, the ECJ's commitment to the doctrines of the supremacy and direct effect of Community law provoked processes that, ultimately, transformed national law and practice. Supremacy required national courts to review the legality of statutes with respect to EC law, and to give primacy to EC norms in any conflict with national norms. For judges in many EU States, the reception of supremacy meant overcoming a host of constitutional orthodoxies, including the prohibition of judicial review of statute, the lex posterior derogat legi priori, and separation of powers notions. These same structural issues arose anew under the Convention", Helen Keller y Alec Stone Sweet, "Assessing the Impact of the ECHR on National Legal System". 
que parece ir totalmente más allá del control de las constituciones nacionales.

En este escenario, el derecho de la UE también ha dado a los jueces nacionales nuevos argumentos para reconsiderar la fuerza del CEDH y el caso italiano es emblemático en este sentido. 